\title{
The Relationships among Sources of Teacher Pedagogical Beliefs, Teaching Experiences, and Student Outcomes
}

\author{
Morteza Mellati (Corresponding author) \\ Department of English, Islamic Azad University, Qom Branch, Qom, Iran \\ PO box 37185-364, Pardisan, Qom, Iran \\ E-mail: mellati.morteza@gmail.com \\ Marzieh Khademi \\ Department of English, Islamic Azad University, Qom Branch, Qom, Iran \\ PO box 37185-364, Pardisan, Qom, Iran \\ E-mail: marzieh.khademi2834@gamil.com \\ Afsaneh Shirzadeh \\ Department of English, Islamic Azad University, Science and Research Branch, Qom, Iran \\ PO box 37185-364, Pardisan, Qom, Iran \\ E-mail: afsane_shirzad@yahoo.com
}

Received: 23-08-2014

Accepted: 29-10-2014

Published: 01-03-2015

doi:10.7575/aiac.ijalel.v.4n.2p.177

URL: http://dx.doi.org/10.7575/aiac.ijalel.v.4n.2p.177

\begin{abstract}
Teachers' beliefs are derived from various sources such as experiences and personality (Kennedy, 1997; Donaghue, 2003; Ellis, 2008), childhood learning experiences (Rokeach, 1968), teaching experiences (Zeichner and Tabachnick, 1981), and folk pedagogy (Bruner, 1996). The relationship of these sources and learners' outcomes are under question; therefore, this study investigated the relationships among sources of teacher pedagogical beliefs, teaching experiences, and student outcomes. The researchers classified these sources into two categories "Experienced Pedagogical Beliefs" and "Educational Pedagogical Beliefs". To conduct this study, 150 Iranian ELT instructors had been chosen randomly. Their students' scores were also used in data analysis. A beliefs' questionnaire and interview were employed to elicit instructors' sources of pedagogical beliefs. The results suggested that a significant proportion of the total variations in learners' outcomes were predicted by teachers' sources of pedagogical beliefs and teachers' teaching experiences. The implications for improving the quality of teacher education programs were also discussed.
\end{abstract}

Keywords: Teacher beliefs, sources of teacher beliefs, teacher education programs, experienced pedagogical beliefs, educational pedagogical beliefs

\section{Introduction}

Most education reforms concentrated on the content of teachers' instructions or teaching methods and have rarely considered what teachers themselves thought about either content or pedagogy (Clark, 1988). However, within the last two decades, research into teachers' beliefs has gained a considerable amount of interest, especially in the area of foreign language teaching and learning (Sage, 2011). In recent decades, more attention has been paid to teachers' beliefs and their roles in the construction of an effective learning environment. Teachers' belief is a mental state that is accepted as true by the individual holding it (Borg, 2001; Liao, 2007; Lucas and Wright, 2009).

Zanting et al. (2001) emphasized that unlike knowledge, a belief is held both consciously or unconsciously and has significant functions in helping individuals make sense of the world, persuade how new information is perceived, and whether it is accepted or rejected. It also draws a framework for individuals' behaviors. Donaghue (2003) claimed that teachers' beliefs play a fundamental role in the teacher development process, especially in the acceptance of new approaches, techniques, and activities. She agreed that teachers' personal beliefs about language teaching, learners and teacher's roles guide teachers in their actual classroom practices. In similar words, other researchers stated that changes in teachers' practices are the consequence of alteration in teachers' beliefs (Richards, et al., 2002; Mansour, 2009; Polat, 2010; Borg, 2011). Considering the stability of teachers' beliefs, Bruner (1996) stated that some beliefs are more important than others to individuals, and the more important the beliefs, the more difficult they are to change. It can be concluded from previous research studies that examining language teachers' beliefs will help elucidate how teachers modify their approaches to teaching and learning over time (Altan, 2006; Eichler, 2006; Tanase and Wang, 2010; Mellati and Khademi, 2014).

Teachers' beliefs are derived from various sources. Some researchers claimed that they are derived from sources such as experiences and personality (Kagan, 1992; Kennedy, 1997; Williams and Burden, 1997; Donaghue, 2003; Ellis, 2008). Some beliefs are derived from childhood learning experiences. It has been argued that beliefs that are linked closely to 
teachers' ego are more important than others (Rokeach, 1968, p. 4). Zeichner and Tabachnick (1981) stated that teachers shape their beliefs in the classroom. They claimed that the main source of teachers' beliefs is their experiences. In a similar point, Bruner (1996) argued that the most significant source of teachers' beliefs is what he called folk pedagogy. Folk pedagogy refers to beliefs that people have in their minds about the characteristics of a good teacher or what they expect from so called good teachers. This view leads to a teacher educator revolutionary insight, which is the practice of education in classrooms. Teacher education programs as another source of teachers' pedagogical beliefs play an important role in shaping teaching quality as well as teachers' beliefs (Finsterwald et al., 2013; Kennedy and Smith, 2013). Teachers' own schooling as young students and observing their own teachers who taught them are the most resistant source of teachers' pedagogical beliefs (Richards et al., 2002; Levin and He, 2008). While significant attention has contributed to understanding the relationship between teachers' beliefs and practices, there have been limited studies that investigate the relationship among sources of teachers' beliefs, teachers' teaching experiences, and student outcomes.

Determining sources of teachers' pedagogical beliefs would be a significant help in designing classroom curriculums and planning effective teaching methods, designs, and strategies for any particular teaching context. There are various sources of teachers' pedagogical beliefs; however, in the present study, based on the obtained results, the researchers themselves classified them into two main categories that were "Experienced Pedagogical Beliefs" and "Educational Pedagogical Beliefs" and also investigated the relationship between these two sources of teachers' pedagogical beliefs and student outcomes. In this classification, the first category is "Experienced pedagogical beliefs" that encompasses pedagogical beliefs that are formed in teachers' own learning and teaching experiences. In this kind of source, teachers' beliefs can be shaped through their lives and are influenced by a variety of factors such as actions, experiences, and other people in their lives (for example, other teachers, students, and parents). Some of these beliefs can be directly adopted from the culture. The second category, "Educational pedagogical beliefs", encompasses pedagogical beliefs that are formed in teacher education programs. Educational materials, structures, and formal teacher education programs are some of the main factors that shaped educational pedagogical beliefs. In other words, "Educational pedagogical beliefs" are those pedagogical beliefs that are established in any teacher education program and "Experienced pedagogical beliefs" are those pedagogical beliefs that are established anywhere except teacher education programs. This kind of belief could derive from teachers' own schooling, teachers' own teaching experiences, observing other teachers, and so on. This particular study had two aims; investigating the relationships between sources of teachers' pedagogical beliefs and students' outcomes as well as the relationships between teachers' teaching experiences and students' outcomes.

\section{Review of literature}

In recent decades, researchers in the field of second language acquisition have shown great interest in teachers' individual personalities that are capable of affecting learners' accomplishment in language learning (Farrell \& Particia, 2005; Altan, 2006). Beliefs about language teaching have been one of these characteristics. Researchers have found that teachers come to the language class with some preconceived beliefs about language and language teaching and that these beliefs can indicate what expectations teachers have and what actions and behaviors in their language teaching they will take (Borg, 2001, 2003, 2006; Donaghue, 2003; Polat, 2010). Perceptions, beliefs, attitudes, and knowledge that teachers bring with them to the teaching context are significant contributory factors in the teaching process and ultimate success of both teachers and learners (Bernat and Gvozdenko, 2005; Ellis, 2008; Hachfeld et al., 2011; Thomson et al., 2012; Khademi et al., 2013). What teachers do in the classrooms is governed by what they believe and these beliefs often serve to act as a filter through which instructional judgments and decisions are made (Eichler, 2006; Mansour, 2009; Philips and Borg, 2009; Hu and Tian, 2012).

Research studies explored factors that help teachers adjust their beliefs and facilitate language teaching (Liao, 2007). They found that teacher education programs that engage teachers in a direct exploration of their pedagogical beliefs and principles may provide the opportunity for greater self-awareness through reflection and critical questioning as starting points for later adaptation, modification, and change (Richards et al., 2002; Bernat \& Gvozdenko, 2005). Pre-service teachers entered teacher education programs with pre-existing ideas about language and language learning, just like learners. Some ideas that the pre-service teachers possess might inhibit their learning of new approaches and techniques in the teacher education programs (Polat, 2010; Tanase and Wang, 2010; Borg, 2011; Levin and He, 2008; Fajet et al., 2005). The formation of teachers' educational beliefs in the language teaching process exerted an imperceptible effect on forming effective teaching approaches and methods. This leads to the enhancement of learners' language learning abilities (Altan, 2006; Brown, 2010; Jimenez and Rose, 2010; Kim et al., 2013). Similarly, some others found that teachers' pedagogical beliefs have a great impact on students' beliefs (Eichler, 2006; Philips and Borg, 2009). The teachers' first year is a crucial and problematic period for them because it shapes teaching patterns and influences teachers' retention. First-year teachers are encouraged to contextualize their subjects and pedagogical preparations; concomitantly be members of a school community; and adjust to its organization and culture (Kagan, 1992). Context and experiences are also other factors that might influence the actualization of reforms; for example, school-based management generally reflects the characteristics of the school in which it is conducted. This suggests that it is ambitious to assume that teachers who have worked in schools and have experienced poor management, inadequate student performance, or lack of attention to teacher's capacity improvement would be able to conduct school development effectively (Tanase and Wang, 2010; Thomson et al., 2012; Kennedy and Smith, 2013; Mellati and Khademi, 2014). In other words, teachers cannot deal with all influential factors (e.g. their beliefs, their learners' beliefs, cultural factors, and school principles) on their own. "Teacher educators need to move away from the traditional 
mainstreaming approach and modify their programs according to changes in student demographics" (Polat, 2010, p. 229). It is evident that teachers' beliefs about language teaching and learning have a powerful effect on teachers' pedagogical decisions and judgments and strongly affect what and how teachers learn during teacher education programs (Philips and Borg, 2009; Bernat \& Gvozdenko, 2005; Tanase and Wang, 2010; Mellati et al., 2013).

Few researchers have focused on sources of teachers' pedagogical beliefs. Some believed that the paramount source of teachers' beliefs is their own learning experiences in schools and these beliefs are resistant to change (Kennedy, 1997; Kagan, 1992; Liao, 2007; Donaghue, 2003; Borg, 2001). Teachers in their classrooms take into account folk theories that are engaged in teaching and learning (Bruner, 1996; Rath, n.d.; Kennedy, 1997). Folk theories are those teaching theories that are transformed by people from one generation to the other. Teachers' own teaching experience is another source of teachers' beliefs. Teachers' beliefs are evaluated, modified, or even changed during teaching experiences (Richards et al., 2002). Teacher education programs that are engaged in language teaching are last but not least source of teachers' belief. Teacher education programs challenge teachers' previously established beliefs. They modify some of those beliefs and change some others (Mansour, 2009; Polat, 2010; Borg, 2011; Kagan, 1992; Kennedy, 1997; Williams \& Burden, 1997).

Notwithstanding a large number of studies on teachers' beliefs, still no research study considered all of its perspectives in an actual practical framework. No study focused on cultural aspects of teachers' beliefs in language study. In this study, the researchers classified these various sources into two main categories and called them "Experienced Pedagogical Beliefs" and "Educational Pedagogical Beliefs". Consequently, they investigated the relationships among sources of teachers' pedagogical beliefs, teaching experiences, and students' outcomes. To achieve the goals of the present correlational study, the following research questions were posed:

1. Is there any relationship between teachers' sources of pedagogical beliefs and their learners' outcomes?

2. Is there any relationship between teachers' teaching experiences and their learners' outcomes?

3. How well do teachers' sources of pedagogical beliefs and teachers' teaching experiences predict learners' outcomes?

\section{Method}

\subsection{Participants}

To conduct the study, the researchers invited some Iranian ELT instructors for participation through email. Out of 800 sent invitations, 150 instructors accepted it. Instructors were informed about the study from the beginning, and that they could withdraw their contributions at any time without penalty. All participants were provided with written information about the nature and purpose of the research project. All of them were insured that their identities in the survey would be held in strict confidence. According to the beliefs' questionnaire that was sent to them through email, the ages of the instructors were in a range of 25 to 60. Forty-five instructors (30\%) were less than 30 and $105(60 \%)$ of them had more than 50 years of age. The proportion of participants' gender was approximately equal (45.8 \% male and $54.2 \%$ female). Twenty nine $(19.3 \%)$ had less than 5 years of teaching experiences, 58 (38.6\%) five to 10 years, $46(30.6 \%)$ instructors 11 to 20 , and $17(11.3 \%)$ had more than 20 years of teaching experiences. For the specific objective of this study, the instructors with teaching experiences less than 5 years were considered as inexperienced and the instructors with teaching experiences more than 5 years were considered as experienced teachers. In addition, to determine the relationship between sources of teachers' pedagogical beliefs and students' outcomes, the researchers employed the scores of the students' general proficiency test. One hundred and fifty scores of the instructors' students were used randomly. Sixty-six of the students (44\%) enrolled in tertiary level and 84 (54\%) in M.A. level.

\subsection{Instrumentations}

The required data was collected through employing following instrumentations:

\subsubsection{Teachers' Beliefs' Questionnaire (TBQ)}

To elicit the sources of teachers' pedagogical beliefs, the researchers employed a beliefs' questionnaire; a researchersmade questionnaire was provided to elicit instructors' sources of pedagogical beliefs about language teaching and their teaching experiences. To make this questionnaire, the researchers obtained main ideas about language teaching from some researches such as Vibulphol (2004), Mohamed, (2006), Liao (2007), Nishino (2008), Rieger (2009), Lin (2010), and Sage (2011). Three experts reviewed it for its content validity and reliability. Next, the collected data of TBQ were subjected to Principal Component Analysis (PCA) with varimax rotation to ensure its construct validity. Based on the results of running PCA, 23 items were omitted and the validated questionnaire comprised 40 items. The final version of TBQ was consisted of 40 Likert-scale items. Then, this researchers-made questionnaire was piloted with 50 instructors of the similar participants. Cronbach's Alpha formula for the inventory was employed; the results showed a reliability index of $0.74(\mathrm{r}=0.74)$.

\subsubsection{Semi-Structured Interview}

To verify the results of the beliefs' questionnaire, the researchers administered a semi-structured interview with twelve instructors; the researchers conducted this 30 minute face-to-face interview to investigate in-depth information about sources of teachers' pedagogical beliefs and to verify the results of the questionnaire. The instructors participated in these interviews voluntarily. Prior to interviewing, they were informed of the purpose and the nature of the study. 


\subsubsection{General Proficiency Test}

To determine the relationships among sources of teachers' pedagogical beliefs, teachers' teaching experiences, and students' outcomes, the researchers used the learners' scores. The general proficiency test was a researchers-made test. It consisted of 30 multiple-choice items. Ten questions were related to vocabulary, 10 questions were related to grammar, five questions to close test, and five questions to a reading passage. This instrument was reviewed by three experts in the field and was piloted with 20 instructors of the similar participants. The Cronbach's alpha coefficient of it was $0.81(\mathrm{r}=0.81)$. The test was in Ms Word format and students should select the correct answers by clicking. The test was sent to the instructors through email.

\subsection{Data collection procedures and data analysis}

In this correlational design study, to determine the relationship between sources of teachers' pedagogical beliefs and students' outcomes, the following procedures were conducted: The sample of this study was selected randomly. Therefore, the researchers collected data from instructors and students in the following procedure: the beliefs' questionnaire was sent to more than 800 ELT Iranian instructors in different universities through email, from which, only 150 were returned. Instructors were informed about the study from the beginning, and that they could withdraw their contributions at any time without penalty. All of them were insured that the identity of them to the survey would be held in strict confidence. To make sure about the genuineness of the instructors, the researchers added clear instructions at the beginning of the questionnaire. Face-to-face semi-structured interviews were also conducted with twelve volunteer instructors in 30 minutes. The interviews were designed to encourage reflection, to elicit sources of teachers' pedagogical beliefs about English language teaching, and to verify the results of the questionnaires. To avoid the instructors' bias, the researchers themselves selected one of the students of each instructor randomly from the sent list. For the students in universities near the location of the researchers, the researchers themselves administered the general proficiency test. The researchers' friends and the instructors themselves administered the rest of the tests. The completed tests were returned to the researchers through email. Students' scores were entered into a data file and analyzed statistically using the Statistical Package for Social Sciences (SPSS), version 18. Statistical analyses carried out on the data included Pearson product-moment correlation coefficient and multiple regressions. Some collected data were qualitative (interviews). They included all open-ended responses to the interviews. The procedure for analyzing qualitative data was as follows: Each data set was read several times to gain some sense of the main ideas being expressed. Then the data were coded and analyzed manually and subjectively.

\section{Results and Discussions}

This study produced results, which corroborate the findings of a great deal of the previous work in this field. Having collected the required data based on the mentioned data collection instruments and procedures, the researchers conducted data analysis and tested the hypotheses formulated for the present study.

The relationship between sources of pedagogical beliefs and learners' outcomes was investigated using Pearson product-moment correlation coefficient. Preliminary analyses were performed to ensure no violation of the assumptions of normality and homoscedasticity. There was a small, negative correlation between the two variables, $\mathrm{r}=.252, \mathrm{n}=150$, $\mathrm{P}<.000$. The $\mathrm{R}$ value of $.252[(\mathrm{r}=.252, \mathrm{P}=.000<.05)]$ indicated that there was a statistically significant relationship between the two variables. Thus, the null-hypothesis as no significant relationship between sources of pedagogical beliefs and learners' outcomes was rejected. The results emphasized that not only teachers' preconceived pedagogical beliefs, but also sources of them should be considered in any teacher education program.

The findings magnify the effect of sources of teachers' pedagogical beliefs even on students' outcomes. Teachers are unique as they had unique experiences in their teaching life, therefore; universal classroom designs and curriculums are not significant. The results of interviews also confirm the above statements. Instructors in the interview stated that corresponding between teachers' beliefs and students' beliefs would result in learning development and mismatch between them lead teachers and students into trouble. They explained equivalent pedagogical beliefs between teachers and students, especially in classes with huge diversity is something impossible; however, it is the ability and in the responsibility of teachers to focus on common beliefs. These beliefs are unique on the part of both teachers and learners in every teaching context.

\section{"I think one of the problems that all teachers face with is the diversity of students in classrooms. They are different and have different interests. So, they prefer different methods. Holding a class in such a situation is somehow difficult, even for professional teachers. Here, the role of teachers is very important and teacher- centered method is the best solution." (Interview)}

Effective teaching and learning happens in circumstances that teachers recognize these common beliefs and concentrate on them in their actual teaching. The findings of the current study are consistent with those of Bernat and Gvozdenko, (2005); Ellis, (2008); Hachfeld et al., (2011); Thomson et al., (2012); and Khademi et al., (2013) who found beliefs and attitudes that teachers bring with them to the teaching context are significant factors in the ultimate success of both teachers and learners. The instructors claimed that there are some teaching contexts that teachers must ignore their beliefs and concentrate more on students' beliefs, needs, and culture.

"Today, many sources of information are in access for students. The materials are available everywhere and students can study them based on their own interests. What's more is that students become familiar with different teaching methods in places such as language institutes and in such kind of place, they [teachers] are allowed to choose a method of teaching that they like [as they] have the purpose to absorb the students to 
themselves, especially for money-making. After that, teachers cannot force them to study according to teacherselected materials in universities. In my opinion, a teaching method would be effective if it reflects on students' interests. I think learner-centered method is more adequate today." (Interview)

This corroborates the ideas of Polat (2010), who suggested teacher educators should move away from the traditional approach and modify their programs according to changes in student demographics.

The relationship between teachers' teaching experiences and learners' outcomes was investigated using Pearson product-moment correlation coefficient. Preliminary analyses were performed to ensure no violation of the assumptions of normality and homoscedasticity. There was a medium, positive correlation between the two variables, $\mathrm{r}=.333, \mathrm{n}=$ $150, \mathrm{P}<.000$. The R-value of $.333[(\mathrm{r}=.333, \mathrm{P}=.000<.05)]$ indicated that there was a statistically significant relationship between the two variables. Thus, the null-hypothesis as no significant relationship between teachers' teaching experiences and learners' outcomes was rejected. In addition, the results of variance proportion indicated that educational pedagogical beliefs have influenced the learners' outcomes more than experienced pedagogical beliefs.

Qualitative results confirmed quantitative ones and asserted that experienced teachers are more powerful in recognizing, modifying, adapting, and altering their pedagogical beliefs. Teaching in different classrooms with diverse students raises teachers' consciousness about effective beliefs in the process of language teaching. It is encouraging to compare this with what was found by Richards et al., (2002) who stated that teachers' beliefs are evaluated, modified, or even changed during teaching experiences.

In the interview, the instructors argued that teacher education programs are important as teaching experiences. In the programs, teachers become familiar with new approaches, teaching methods, and strategies that are along with their already existed beliefs. In cases that programs are in contrast to the previous beliefs, teachers have challenge to resist on their beliefs or modify or even change them. This finding is in agreement with Liao, (2007); Polat, (2010); Williams and Burden, (1997); and Donaghue's, (2003) findings that showed teacher education programs challenge teachers' previous established beliefs. They modify some of those beliefs and change some others. The instructors stated that the most challenging time for teachers is the first year of teaching practice. They face with actual teaching environments, diverse students, different cultures, and many other contradictions. Even those teachers that are fully aware of their beliefs have difficulties to follow them. Some external factors such as curriculum policies, culture, personality, and learners' age, beliefs, and needs are obstacles that even sophisticated teachers have to modify their established pedagogical beliefs.

"Teachers have other problems rather than lack of experience or a mixture of the students in the classroom. Language policy can affect teachers largely. They cannot follow their beliefs because of political language polices. Students also have different purposes; a variety of purposes along with a variety of preferences create a complex situation that even professional teachers would not able to handle it." (Interview)

Concomitantly, Kagan, (1992) found that the teachers' first year is a crucial and problematic period for them because it shapes teaching patterns and influences teachers' retention.

A multiple linear regression analysis was conducted to determine if the learners' scores (dependent variable) could be predicted from sources of pedagogical beliefs and teachers' teaching experiences (independent variables or predictor variables). The null hypothesis stated that the regression coefficient was equal to zero $(R=0)$. The data were screened for violation of assumptions prior to analysis. There were no missing data. Preliminary analyses were conducted to ensure no violation of the assumptions of normality, linearity, multicollinearity, and homoscedasticity. The results of the multiple regression suggested that a significant proportion of the total variation in learners' outcomes was predicted by teachers' sources of pedagogical beliefs and teachers' teaching experiences; $\mathrm{R}$ squared change $=.15$, F change $(2,148)$ $=32.755, \mathrm{P}<.001$. In other words, the $\mathrm{R}=0.15$ indicated that about $15 \%$ of the variation in learners' outcomes about its mean is explained by variations in teachers' sources of pedagogical beliefs and teachers' teaching experiences. The obtained value is a remarkable one that needs more consideration in teacher education programs. The results indicated that the third null hypothesis that teachers' sources of pedagogical beliefs and teachers' teaching experiences do not predict learners' outcomes was rejected. The results also revealed that about $58 \%$ of these variations were due to teachers' teaching experiences and about $42 \%$ of them manifested by sources of pedagogical beliefs. Therefore, the null hypothesis that there is no difference between teachers' sources of pedagogical beliefs and teachers' teaching experiences in predicting learners' outcomes was rejected.

The results of interviews demonstrated that teachers had different sources of pedagogical beliefs. They stated that without considering their sources of pedagogical beliefs, teachers are encountered to act based on their beliefs in the classrooms; therefore, paying attention to this significant point in teacher education programs is necessary. They also claimed that determining obstacles and obviating them require dedicating a large amount of time and money since recognizing abstract sources of pedagogical beliefs is an intricate task. One of the most prominent teacher education programs as the instructors claimed is self-awareness about beliefs. They claimed that if teachers become aware of their beliefs, the chance to modify and change them would be increased to a large extent. Recognizing teachers' beliefs in the instructors' opinion is the key factor to adapt or change them. In similar statements, and Richards et al., (2002) argued that teacher education programs engage teachers in a direct exploration of their pedagogical beliefs and might provide the opportunity for greater self-awareness through reflection and critical questioning. This is the major factor for later adaptation, modification, and change.

\section{Conclusion}

Teachers' beliefs studies in two decades revealed that they influence the pedagogical decisions about teaching of both 
inexperienced and experienced teachers and teachers' practices derive from those pedagogical decisions (Borg, 2001; Donaghue, 2003; Eichler, 2006; Liao, 2007; Polat, 2010). Teachers' prior beliefs serve as a filter to what is learned during teacher education programs (Kagan, 1992; Clark, 1988; Farrell and Particia, 2005; Hachfeld et al., 2011).

The present study was designed to determine the connection of sources of teachers' pedagogical beliefs and students' outcomes. It also investigated the relationship between teachers' teaching experiences and students' outcomes. One of the significant findings that emerges from this study is that the teachers' awareness of their pedagogical beliefs has a magnificent effect on the teachers' decision, teaching approaches, teaching opportunities, and classroom practices. Teachers' beliefs are unique in every teaching context; therefore, universal classroom designs and curriculums are inadequate. Returning to the hypotheses posed at the beginning of this study, it is possible to state that a significant proportion of the total variations in learners' outcomes were predicted by teachers' sources of pedagogical beliefs.

The findings of the present study corroborated the ideas of Levin and He (2008), who suggested that the sources of pedagogical beliefs are intervened in what is learned during teacher education. It is claimed that early beliefs are stable and subsequent teacher education programs appear not to disturb these early beliefs (Johnson, 1992); however, the findings of the current study stated that sources of pedagogical beliefs can and do influence teachers' beliefs during their teacher education program. In conformity with Hachfeld et al. (2011), through structuring the learning environment, teachers play a pivotal role in student learning. Teachers' pedagogical beliefs significantly influence how they plan, organize, and implement their lessons as well as how responsive they are to their students. In addition to corroborating a large number of previous works, the study posed new challenges that are the most effective textbooks are local textbooks and these textbooks should be taught based on that local teachers' beliefs. In the circumstances that teachers have inefficient teaching beliefs, the teacher educators should design effective teacher education program that modifies teachers' beliefs.

The findings have important implications for developing appropriate teacher education programs. Recognizing and understanding teachers' sources of pedagogical beliefs are essential to developing teaching practices and teacher education programs (Farrell and Particia, 2005), since teachers will not adopt a new set of practices unless they believe in it (Ur, 1996). Since the findings demonstrated that teacher education programs have influence on teachers' beliefs about curriculum design, classroom context, roles, and responsibilities of teachers, policy makers and curriculum designers might pay considerable attention to sources of pedagogical beliefs in their future programs. In addition, the findings revealed that greater experience does not lead to greater adaptability in teachers' beliefs (Richards et al., 2002); therefore, teacher trainers might be more successful if they focus on novice teachers. Consequently, it is hoped that the novice pre-service or in-service teachers, while they are in teacher education programs, modify their pedagogical beliefs and enhance their teaching. Teacher educators should teach novice teachers how to deal with different teaching context and how to come up with new ways through existed obstacles. Local classroom designs and curriculums are the eternal solutions to teaching difficulties. At the outset of every teaching context, teachers and learners should determine their beliefs. Final lesson plan and curriculum should be designed based on the determined teachers' beliefs. Extending this knowledge would also require longitudinal research in the future studies. Furthermore, each source of teachers' pedagogical beliefs is tentative to manifold researches to manifest the abstract and hidden facts of pedagogical beliefs and their effects on teacher education programs.

\section{References}

Altan, M. X. (2006). Beliefs about language learning of foreign language- major university students. Australian Journal of Teacher Education, 31(2), 45-52. Retrieved on June, 2012 from http://ro.ecu.edu.au/ajte/vol31/iss2/5

Bernat, E. \& Gvozdenko, I. (2005). Beliefs about language learning: Current knowledge, pedagogical implications, and new research directions. TESL-EJ, 9(1). Retrieved on May, 2011 from http://www-writing.berkeley.edu/TESLEJ/ej33/a1.html

Borg, M. (2001). Key concepts in ELT teachers' beliefs. ELT Journals, 55(2), 186-188.

Borg, S. (2003). Teacher cognition in language teaching: A review of research on what language teachers think know believe and do. Language Teaching, 36(2), 81-109. DOI: 101017/S0261444803001903

Borg, S. (2006). Teacher cognition and language education. London: Continuum.

Borg, S. (2011). The impact of in-service teacher education on language teachers' beliefs. System, 39, 370-380. Doi:10.1016/j.system.2011.07.009

Brown, C. P. (2010). Children of reform: The impact of high-stakes education reform on pre-service teachers. Journal of Teacher Education, 61(5), 477-491. Doi: 10.1177/0022487109352905. Retrieved on February, 2013 from http://jte.sagepub.com/content/61/5/477

Bruner, J. (1996). The culture of education. Cambridge, MA: Harvard University Press.

Clark, C. (1988). Asking the right questions about teacher preparation: Contributions of research on teaching thinking. Educational Researcher, 17(2), 5-12.

Donaghue, H. (2003). An instrument to elicit teacher's beliefs and assumptions. ELT Journals, 57(4), 344-351.

Eichler, A. (2006). Individual curricula - beliefs behind teachers' beliefs. ICOTS, 7, 1-6. 
Ellis, R. (2008). The study of second language acquisition. 2 Edition. Oxford: Oxford University Press.

Fajet, W., Bello, M., Leftwich, S. A., Mesler, J. L., Shaver, A. N. (2005). Pre-service teachers' perceptions in beginning education classes. Teaching and Teacher Education, 21, 717-727. Doi:10.1016/j.tate.2005.05.002

Farrell, C. S. T., \& Particia, C. P. L. (2005). Conceptions of grammar teaching: a case study of teachers' beliefs and classroom practices. TESL-EJ Top, 2(9), 1-13.

Finsterwald, M., Wagner, P., Schober, B., Lüftenegger, M., Spiel, C. (2013). Fostering lifelong learning - evaluation of a teacher education program for professional teachers. Teaching and Teacher Education, 29, 144-155. http://dx.doi.org/10.1016/j.tate.2012.08.009

Hachfeld, A., Hahn, A., Schroeder, S., Anders, Y., Stanat, P. (2011). Assessing teachers' multicultural and egalitarian beliefs: the teacher cultural beliefs scale. Teaching and Teacher Education, 27, 986- 996. Doi:10.1016/j.tate.2011.04.006

Hu, B., \& Tian, L. (2012). Do teachers and students share similar beliefs about teaching and learning strategies? System, 1, 1-18. Doi:10.1016/j.system.2012.04.001

Jimenez, R. T., \& Rose, B. C. (2010). Knowing how to know: Building meaningful relationships through instruction that meets the needs of students learning English. Journal of Teacher Education, 61(5), 403-412. Doi: 10.1177/0022487110375805. Retrieved on June, 2012 from http://jte.sagepub.com/content/61/5/403

Johnson, K. E. (1992). The relationship between teachers' beliefs and practices during literacy instruction for non-native speakers of English. Journal of Reading Behavior, 24, 83-108.

Kagan, D. M. (1992). Implications of Research on Teacher Belief. Educational Psychologist, 27, 65-90.

Kennedy, M. M. (1997). Defining an ideal teacher education program. NCATE.wpd, Michigan State University, 1-29.

Kennedy, S. Y., \& Smith, J. B. (2013). The relationship between school collective reflective practice and teacher physiological efficacy sources. Teaching and Teacher Education, 29, 132-143. http://dx.doi.org/10.1016/j.tate.2012.09.003

Khademi, M., Motallebzadeh, K., \& Ashraf, H. (2013). The relationship between Iranian EFL instructors' understanding of learning styles and their students' success in reading comprehension. English Language Teaching, 6(4), 134-142. doi:10.5539/elt.v6n4p

Kim, C., Kim, M. K., Lee, C., Spector, J. M., DeMeester, K. (2013). Teacher beliefs and technology integration. Teaching and Teacher Education, 29, 76-85. http://dx.doi.org/10.1016/j.tate.2012.08.005

Levin, B., \& He, Y. (2008). Investigating the content and sources of teacher candidates' Personal Practical Theories (PPTs). Journal of Teacher Education, 59(1), 55-68. Doi: 10.1177/0022487107310749. Retrieved on May, 2011 from http://jte.sagepub.com/cgi/content/abstract/59/1/55

Liao, P. (2007). Teachers' beliefs about teaching English to elementary school children. English Teaching \& Learning, $31(1), 43-76$.

Lin, H. C. (2010). A case study: An ESL teacher's beliefs and classroom practices in grammar instruction. Unpublished doctoral dissertation, Minghsing University of Science and Technology.

Lucas, S. B., \& Wright, V. H. (2009). Who am I? The influence of teacher beliefs on instructional technology incorporation. Journal on Excellence in College Teaching, 20(3), 77-95.

Mackey, A., \& Gass, M. S. (2005). Second language research: Methodology and design. Mahvah, NJ: Lawrence Erbaum Associates.

Mansour, N. (2009). Science teachers' beliefs and practices: issues, implications and research agenda. International Journal of Environmental \& Science Education, 4(1), 25-48.

Mellati, M. \& Khademi, M. (2014). ELT learners' preferences and teachers' attitudes: Determinant factors in curriculum design. International Journal of Language Learning and Applied Linguistics World, 5(3), 258-273.

Mellati, M., Fatemi, M. A., \& Motallebzadeh, K. (2013). The relationship between Iranian ELT instructors' beliefs about language teaching and their practices in real classrooms. English Language Teaching; 6(4), 126-133. Doi:10.5539/elt.v6n4p126

Mohamed, N. (2006). An exploratory study of the interplay between teachers' beliefs, instructional practices, \& professional development. Unpublished doctoral dissertation, University of Auckland- Auckland.

Nishino, T. (2008). Japanese secondary school teachers' beliefs and practices regarding communicative language teaching: an exploratory survey. JALT Journal, 30(1), 27- 51.

Philips, S., \& Borg, S. (2009). Exploring tensions between teachers' grammar teaching beliefs and practices. System, 37, 380-390. Doi:10.1016/j.system.2009.03.002

Polat, N. (2010). Pedagogical treatment and change in pre-service teacher beliefs: an experimental study. International Journal of Educational Research, 49, 195-20. Doi:10.1016/j.ijer.2011.02.003

Raths, J. (n.d.). Teachers' beliefs and teaching beliefs. ELT Journal, 385-395. 
Richards, C. J., Gallo, B. P., Renandya, A. V. (2002). Exploring teachers' beliefs and the processes of change. SEAMEO Regional Language Centre, Singapore, 1-17.

Rieger, B. (2009). Hungarian university students' beliefs about language learning: A questionnaire study. WoPaLP, 3 , 97-113.

Rokeach, M. (1968). Beliefs, attitudes, and values. San Francisco: Jossey-Bass.

Sage, C. M. (2011). Learner beliefs in South Korea: Enriching the description. Electronic Journal of Foreign Language Teaching, 8(2). 216-233. Retrieved on June 2012 from http://e-flt.nus.edu.sg/

Thomson, M. M., Turner, J. E., Nietfeld, J. L. (2012). A typological approach to investigate the teaching career decision: Motivations and beliefs about teaching of prospective teacher candidates. Teaching and Teacher Education, 28, 324335. Doi:10.1016/j.tate.2011.10.007

Ur, P. (1996). A course in language teaching: Practice \& theory. Cambridge, England: Cambridge University Press.

Vibulphol, J. (2004). Beliefs about language learning and teaching approaches of pre-service EFL teachers in Thailand. Unpublished doctoral dissertation, Chulalongkorn University- Bangkok, Thailand.

Williams, M., \& Burden, L. R. (1997). Psychology for language teacher: A social constructivist approach. Cambridge University Press.

Zanting, A., Verloop, N., Vermunt, D. J. (2001). Student teachers eliciting mentors' practical knowledge and comparing it to their own beliefs. Teaching and Teacher Education, 17, 725-740.

Zeichner, K. M., \& Tabachnick, B. R. (1981). Are the effects of university teacher education washed out by school experience? Journal of Teacher Education, 32(3), 7-11. 